\title{
Primary hepatocellular carcinoma arising in a renal transplant recipient with polycystic disease
}

\author{
B. P. GARDNER* \\ M.R.C.P., F.R.C.S. \\ D. B. EVANS \\ F.R.C.P. \\ Transplant Unit, New Addenbrooke's Hospital, Hills Road, Cambridge, Cambridgeshire
}

\begin{abstract}
Summary
Malignant disease arises more commonly in renal transplant recipients than in non-transplanted individuals. Renal polycystic disease is the only cause of renal failure that has a statistically significant association with the acquisition of malignancy in renal transplant recipients. This patient, who had renal failure due to polycystic disease, is the first reported renal transplant recipient to develop a hepatocellular carcinoma in an otherwise completely normal liver.

It is suggested that patients with polycystic renal disease may have an unidentified factor that predisposes to the development of malignancy in them after transplantation.
\end{abstract}

KEY WORDS: renal transplant, polycystic disease, immunosuppression, hepatocellular carcinoma.

\section{Introduction}

Two cases of hepatocellular carcinoma arising in renal transplant recipients have been recorded. One had renal failure due to chronic pyelonephritis and had evidence of severe fatty change with haemosiderin deposits in the liver at post mortem (Arbus and Hung, 1972). The other had renal failure due to chronic glomerulonephritis and had a hepatitis B positive chronic active hepatitis with early cirrhosis (Pritzker, 1972). The patient reported here was a renal recipient who developed hepatocellular carcinoma in an otherwise completely normal liver. His renal failure was due to polycystic renal disease. Polycystic renal disease is the only cause of renal failure that has a statistically significant association with the acquisition of malignancy in transplant recipients (13th Report of the Human Renal Transplant Registry, 1977).

\section{Case report}

A 51-year-old man presented in December 1973

\footnotetext{
*Present address: Neurosurgical Unit, Royal Victoria Hospital, Belfast BT 12 6BA.
}

with chronic renal failure due to polycystic ren⿳亠丷厂 disease. Haemodialysis was commenced in October 1974. Bilateral nephrectomy was performed in Maroh 1975 to prevent further episodes of painful haematuria. A right-sided renal transplant was performed in May 1975 and standard immunosuppression with azathioprine and prednisone was initiated. This graft functioned well until his death 29 months later. In August 1977, he developed right upper quadrat pain, anorexia and an epigastric mass and wis admitted for investigation. Hepatitis B surface an gen (HBs) and both surface antibody (Anti-HBsfand core antibody (Anti-HBc) were negative. His $\frac{\text { Tueer }}{4}$ function tests were normal on admission. A Fiver biopsy was performed and histology indicated the had a hepatocellular carcinoma. A few days follo ing this biopsy he developed a Gram-negatioe septicaemia and died. At post mortem, the diagnogूs of hepatocellular carcinoma was confirmed. Thewe was no evidence of cirrhosis, polycystic or other livgr disease. There was no evidence of renal transplant rejection.

\section{Discussion}

It has been well established that renal transplanit recipients have an increased risk of developing ${ }_{3}$ malignancy and that recipients of organs from donors with malignancy may develop the donots malignancy. However, organ replacement for malisnancy is not necessarily followed by massive growth of the malignancy. In a review of 19,631 renfy1 recipients, 290 malignancies were reported (13,th Report of the Human Renal Transplant Regist 1977). The commonest malignancy was 'reticulưm cell sarcoma'. Most of the other malignancies weixe other lymphomas, superficial skin malignancies at cervical carcinoma in situ. The three malignanciss that occurred in the homograft recipients treated with cyclosporin A were all lymphomas (Calne et ap, 1979). It has been calculated that the risk of a rengl 
recipient developing a 'reticulum cell sarcoma' is 350 times greater than expected and it has been shown that cerebral involvement in such cases is much commoner than usual, possibly because the brain is an immunologically privileged site. It is not clear why transplant recipients have an increased incidence of de novo malignancy, but various explanations have been put forward. Firstly, immunosurveillance is impaired by immunosuppressive drugs (Penn and Starzl, 1973). However, this is unlikely to be the sole reason for the increased incidence of malignancy since the distribution in the type of malignancy is so different from that of the normal population and non-immunosuppressed mouse homograft recipients may develop malignant lymphomas (Myking, 1969). Secondly, the transplanted tissue acts as a large mass of antigen stimulating the lymphoreticular system and, thirdly, it has been suggested that virus activation may be important. Ninety per cent of transplant recipients get clinical or serological evidence of herpes simplex virus infection and there is good evidence that the Epstein-Barr virus is involved in the induction of some lymphomas (Matas, Simmons and Najarian, 1975). Chronic irritation predisposes to malignancy in several situations in otherwise healthy individuals. The patient reported here had a completely normal liver before he developed hepatocellular carcinoma and no other cause of hepatocellular carcinoma was detected in him. This fact, together with the reported statistical association of renal polycystic disease with malignancy in transplant recipients, suggests that renal transplant recipients, whose renal failure was due to polycystic disease, have an unidentified factor present in them that predisposes to the development of malignancy.

\section{Acknowledgments}

We wish to thank Professor R.Y. Calne for permission to publish this report, and Dr J. Nagington of the Virology Department, New Addenbrooke's Hospital, for his assistance.

\section{References}

ARBUS, G.S. \& HUNG, R.H. (1972) Hepatocarcinoma and myocardial fibrosis in an $8 \frac{3}{4}$ year old renal transplant recipient. Canadian Medical Association Journal, 107, 431.

Calne, R.Y., Rolles, K., Thiru, S., McMaster, P., Craddock, G.N., Aziz, S., White, D.J.G., Evans, D.B., DunN, D.C., HeNDERSON, R.G. \& LEWIS, P. (1979) Cyclosporin A initially as the only immunosuppressant in 34 recipients of cadaveric organs: 32 kidneys, 2 pancreases and 2 livers. Lancet, ii, 1033.

Matas, A.J., Simmons, R.L. \& NaJarian, J.S. (1975) Chronic antigenic stimulation, herpes virus infection and cancer in transplant recipients. Lancet, i, 1277.

MYKING, A.O. (1969) Immunosuppression and cancer (letter). Lancet, i, 731.

PenN, I. \& STARzL, T.E. (1973) Immunosuppression and cancer. Transplantation Proceedings, V, 943.

PritzKer, K. (1972) Neoplasia in renal transplant recipients (letter). Canadian Medical Association Journal, 107, 1059.

13th REPORT OF THE HUMAN RENAL TRANSPLANT REgISTRY (1977) Transplantation Proceedings, IX, 9.

(Accepted 14 May 1982) 